\title{
Meme Kanseri Cerrahisi Sonrası Lenfödem ve Uçak Seyahati
}

\author{
Aysel GÜL*, Dilek AYGIN**
}

\begin{abstract}
$\ddot{O} \mathbf{z}$
Meme kanseri, küresel düzeyde önemli morbidite ve mortalite nedenlerinden biridir ve her geçen gün insidansı giderek artmaktadır. Meme kanseri tedavisine yönelik kişiye özgü, lokal/sistemik birçok uygulama kullanılmaktadır. Lenfödem, meme kanseri tedavisinin en yaygın görülen kronik komplikasyonudur. Bireylerin yaşam kalitesini olumsuz yönde etkileyerek fiziksel ve/ veya psikolojik birtakım sorunlara yol açmaktadır. Dolayısıyla meme kanseri tedavisi bireylerde yaşam tarzı değişikliklerine neden olmakta, birtakım önleyici tedbir ve uygulamaları da beraberinde getirmektedir. Bu noktada endişe duyulan konulardan biri, uçakla seyahatin meme kanseri cerrahisi sonrası lenfödem gelişimi üzerindeki negatif etkilerinin bilinmesidir. Özellikle meme kanseri ve tedavisi sonrası uçak seyahatinin lenfödem tablosunu şiddetlendirdiği görüşü yaygındır. Hava yolu ulaşımının popüler hale geldiği günümüzde, meme kanseri ve tedavisi nedenli lenfödem gelişiminin, bireylerin günlük ve sosyal yaşamlarını etkilediği açıtıtır. Hava yolu seyahati sonrası lenfödem gelişme riski, hastaları birtakım davranışsal yöntemleri kullanmaya itmiştir. Bu davranışsal önlemlerin bir kısmı, önerilen kompresyon cihazların kullanımı, seyahatlerin ertelenmesi ve seyahat süre ya da yöntemlerinde değişiklikler yapılması şeklinde olmuştur. Ancak literatürde konuya ilişkin yapılan sınırlı sayıdaki çalışmada çelişkili sonuçlar yer almaktadır ve bu konuda hem klinisyenlerin hem de hastaların bilgi gereksinimlerinin giderilmesi gerekmektedir. Bu derleme, uçak seyahatinin, meme kanseri ve cerrahisi sonrası lenfödem gelişimi üzerindeki etkisine ilişkin literatürün incelenmesi ve sonuçlarının değerlendirilmesi amacıyla yazılmıştır.
\end{abstract}

Anahtar Sözcükler: Meme kanseri, cerrahi, lenfödem, uçak, seyahat, hemşirelik.

\section{Lymphedema and Air Travel After Breast Cancer Surgery}

\begin{abstract}
Breast cancer is one of the major causes of morbidity and mortality globally, and its incidence is increasing day by day. Many personalized local/systemic applications are used for breast cancer treatment. Lymphedema is the most frequently seen chronic complication of breast cancer treatment. It causes certain functional and/or psychological problems by affecting the life quality of individuals in a negative manner. Consequently, breast cancer treatment causes lifestyle changes in individuals, and it leads to several preventive measures and practices. One of the issues of concern at this point is to know the negative effects of air travel on lymphedema development after breast cancer surgery. In particular, it is widely believed that air travel after breast cancer and its treatment exacerbates lymphedema. It is clear that the development of lymphedema due to breast cancer and its treatment affects the daily and social lives of individuals today when air transportation has become popular. The risk of developing lymphedema after air travel has pushed patients to use some behavioral methods. Some of these behavioral measures were the use of recommended compression devices, delay of travel and changes in travel time or methods. However, there are conflicting results in the limited number of studies conducted on the subject in the literature, and the information needs of both clinicians and patients should be met. This review was written to examine the literature on the effect
\end{abstract}

Derleme Makale (Review Article)

Geliş / Received: 28.08 .2021 \& Kabul / Accepted: 13.12.2021

DOI: https://doi.org/10.38079/igusabder.987931

* Arş. Gör., Sakarya Üniversitesi, Sağlık Bilimleri Fakültesi, Hemşirelik Bölümü, Sakarya, Türkiye,

E-posta: ayselgul@sakarya.edu.tr ORCID https://orcid.org/o000-0002-0073-8916

*** Prof. Dr., Sakarya Üniversitesi, Sağlık Bilimleri Fakültesi, Hemşirelik Bölümü, Sakarya, Türkiye,

E-posta: daygin@sakarya.edu.tr ORCID https://orcid.org/0000-0003-4620-3412 
of air travel on the development of breast cancer and post-surgical lymphedema, and to evaluate its results.

Keywords: Breast cancer, surgery, lymphedema, aircraft, travel, nursing.

\section{Giriş}

Meme kanseri yüksek morbidite ve mortalite oranlarıyla tüm dünyada görülme sıklığı giderek artan önemli bir sağllk sorunudur ${ }^{1,2}$. Küresel düzeyde önde gelen ölüm nedenlerinden biri olan kanserlerin büyük bir kısmının etiyolojisini meme kanserleri oluşturmaktadır3. Amerikan Kanser Derneği'nin verilerine göre, ABD'de 2020 yllı sonuna kadar yaklaşık 276.480 yeni invaziv meme kanseri, 48.530 ise yeni in situ karsinom vakasının teşhis edileceği ve 42.170 bireyin bu etiyoloji nedeniyle hayatını kaybedeceği tahmin edilmektedir4. Global Kanser İstatistikleri 2020 verilerine göre Türkiye'de meme kanseri insidansı \%10.6 olarak (22 345 birey, her iki cinsiyet, tüm yaşlar) hesaplanmıştır. Aynı raporda, Türkiye'de yaklaşık her dört kadından birinin (\%24.4) meme kanseri tanısı aldığı ve mortalite oranları açısından \%4.7'sinin (5 452 birey) ikinci sırada meme kanserine bağlı hayatını kaybettiği bildirilmektedir5.

Meme kanseri tanısı ne kadar erken dönemde konursa, sağ kalım oranları önemli ölçüde artmaktadır. İlk evrede (evre I) teşhis edilenlerde (\%62.5) hastalık yönetimi ile tedavi ve bakım süreçlerinin denetiminin sağlanması ile beş yıllık sağ kalım oranlarının \%98.8’lere kadar ulaştığı, mortalite oranlarını da ciddi boyutta etkilediği bilinmektedir ${ }^{6}$. Ancak son çeyrek yüzyılda hem kadın hem de erkeklerde meme kanseri insidansında bir artış söz konusu olmuştur ${ }^{7}$. Amerikan Kanser Topluluğu verilerine göre 2020 yılında erkeklerde 2620 yeni meme kanseri görüleceği ve bunlardan 520'sinin hayatını kaybedeceği öngörülmektedir8. Özellikle kadın meme kanserleri vakalarında tedavi başarı oranları ve genel sağ kalım, mamografi taramalarında artış, adjuvan kemoterapi, insan epidermal büyüme faktörü reseptörü 2 tedavisi ve endokrin tedavisi gibi tanı ve tedavi süreçlerinde yaşanan gelişmelerle iyileşme göstermektedir'. Fakat erkek meme kanserlerinin kadınlara kıyasla daha nadir görülmesi ve bu konuda yapılan çalışmaların retrospektif oluşu, tedavi seçeneklerine ilişkin yeterli kanıt sunmadığından, her iki cinsiyet için hastalık prognoz ve tedavi seçeneklerine yönelik farklılıkları ortaya koymayı zorlaştırmaktadır ${ }^{10}$.

Kanserden kurtulan bireyler tedavi sonrası hastalık ve tedavilerin psikososyal ve fiziksel sorunlarıyla baş etmeye çalışmakta, yaşam kalitesini istenilen düzeyde sürdürememe endişesi yaşamaktadırlar ${ }^{11}$. Hastalar tedavi sonrası yaşadıkları psikososyal sorunların ${ }^{12-14}$ yanı sıra seroma $^{15}$, hematom ${ }^{16}$, aksiller web sendromu ${ }^{17}$, post mastektomi ağrı sendromu ${ }^{18}$, fantom meme ağrıs1 ${ }^{19}$, eklem ağrılar1 ${ }^{20}$, yara enfeksiyonu ${ }^{21}$, etkilenen ekstremite hareket kısıtlllığ $1^{22}$, yorgunluk ${ }^{12}$, uyku problemleri ${ }^{23}$ ve lenfödem ${ }^{15}$ gibi fiziksel sorunlarla baş etmek durumundadırlar.

Meme kanseri ve cerrahi sonrası lenfödem gelişimi ile uçak seyahati yapılıp yapılmaması konusunda sınırlı sayıdaki örneklemle gerçekleştirilen, az sayıdaki araştırmadan elde edilen bulguların farklılık gösterdiği dikkati çekmektedir. Bu konuda hem klinisyenlerin hem de hastaların bilgi gereksinimi olduğu ve net yanıt alamadıkları görülmektedir. Özellikle konuya ilişsin kanıt değeri yüksek yayınlarla hazırlanmış olan kılavuzların olmadığı tespit edildi. Bu konunun aydınlatılmasına yönelik bilimsel verilerin incelenmesi gerektiğinden hareketle bu derleme, uçak seyahatinin, meme kanseri ve cerrahisi sonrası lenfödem gelişimi üzerindeki etkisine ilişkin literatürü incelenmek ve çalışma sonuçlarını değerlendirmek amacıyla planlandı. $\mathrm{Bu}$ konuda yapılmış olan çok az sayıda çalışma olduğu görüldü ve Tablo 1'de çalışmalardan elde edilen sonuçlar özet olarak verildi.

Meme kanseri cerrahisi sonrası lenfödem gelişimi ve uçak seyahati arasındaki ilişkiyi tespit etmek amacıyla yapılan araştırma sonuçları heterojen bir dağılım gösterir (Tablo 1). Sadece bir 
çalışmada (1996) uçak seyahatinin lenfödem gelişimine neden olduğu ve prognozu kötüleştirdiği belirlenmiştir. Başka bir araştırmada (2002) ise az sayıda hastada lenfödemi ağırlaştığı, kısa mesafeli uçuşlarda seyahatin, düşük bir risk faktörü olduğu tespit edilmiştir. Yapllan bu 10 çalışmanın yedisinde ise hava yolculuğu ile lenfödem gelişimi arasında anlamlı bir ilişki bulunamamıştır.

Tablo 1. Lenfödem ve uçak seyahati ilişkisi inceleyen çalışmalar

\begin{tabular}{|c|c|c|c|}
\hline Yazar/lar & $\begin{array}{l}\text { Çalışmanın } \\
\text { Türü / } \\
\text { Vaka Sayısı }\end{array}$ & $\begin{array}{l}\text { Çalışmanın Metodolojisi } \\
\text { (Kullanılan İçerikler) }\end{array}$ & Elde Edilen Sonuçlar \\
\hline $\begin{array}{l}\text { Casley } \\
\text { Smith. } \\
(1996)^{24}\end{array}$ & $\begin{array}{l}\text { Retrospektif } \\
\text { anket } \\
\text { çalışması } \\
-490 \text { hasta }\end{array}$ & $\begin{array}{l}1020 \text { lenfödem hastasına anket } \\
\text { gönderilmiştir. Bunlardan } 749 \text { 'u } \\
\text { tamamına cevap verirken, } 531 \text { hasta } \\
\text { durumu neyin tetiklediğine ilişkin } \\
\text { sadece bir soruya cevap vermiştir. }\end{array}$ & $\begin{array}{l}490 \text { hastada lenfödem geliştiği tespit } \\
\text { edilmiştir (163 hastada mastektomi } \\
\text { sonrası lenfödem, } 136 \text { primer ve } 191 \\
\text { hastada sekonder bacak ödemi). } \\
490 \text { hastanın } 27 \text { 'sinde görülen } \\
\text { lenfödemin uçak seyahati sırasında } \\
\text { başladığı belirlenmiştir (Bunlardan 15’i } \\
\text { bacak ve 12'si kolda olmak üzere). Buna } \\
\text { ek olarak uçak seyahatinin } 749 \text { hastanın } \\
\text { 23’ünün kol, } 44 \text { kişinin de bacağındaki } \\
\text { mevcut lenfödemin kötüleşmesine neden } \\
\text { olduğu bulunmuştur. }\end{array}$ \\
\hline $\begin{array}{l}\text { Graham. } \\
(2002)^{25}\end{array}$ & $\begin{array}{l}\text { Retrospektif } \\
\text { anket } \\
\text { çalışması } \\
\text {-287 hasta }\end{array}$ & $\begin{array}{l}\text { Patolojileri, tedavi ayrıntıları bilinen ve } \\
\text { kol çevresi ölçülen relaps görülmeyen } \\
293 \text { hasta uçuş maruziyeti ve önlem } \\
\text { yöntemlerine karşı incelemeye alınmış, } \\
\text { bunlardan 287'si yanıt vermiştir. }\end{array}$ & $\begin{array}{l}287 \text { hastanın yarısından fazlasının } \\
\text { (\%50,5) uçak seyahati yaptığı, \%27'sinin } \\
\text { deniz aşırı ülkeleri tercih ettiği } \\
\text { belirlenmiştir. } \\
\text { Ortalama uçuş sayısı 5.3’tür. Hastaların } \\
\text { \%24’ü lenfödem önlemleri almış, \%9o’ı } \\
\text { kompresyon tekniklerini kullanmıştır. } \\
\text { Uçuştan sonra } 16 \text { hastada lenfödem } \\
\text { kötüleşmiştir. } \\
\text { Kısa mesafeli (<4.5 saat) uçak } \\
\text { seyahatinin lenfödem gelişimi için düşük } \\
\text { risk taşıdığı ve kompresyon cihazlarının } \\
\text { muhtemelen verimsiz olduğu sonucuna } \\
\text { ulaşılmıştır. }\end{array}$ \\
\hline $\begin{array}{l}\text { Hayes et al. } \\
(2005)^{26}\end{array}$ & $\begin{array}{l}\text { Retrospektif } \\
\text { gözlemsel } \\
\text { çalışma } \\
-176 \text { hasta }\end{array}$ & $\begin{array}{l}\text { Meme kanseri cerrahisinden altı ay } \\
\text { sonra lenfödem varlığı çok frekanslı } \\
\text { biyoelektrik empedansı, kol çevresi } \\
\text { ölçümü ve bireysel bildirim kullanılarak } \\
\text { değerlendirilmiştir. }\end{array}$ & $\begin{array}{l}\text { Kol çevresi toplamı arasındaki farklar } \\
\text { (fark }>5 \mathrm{~cm} \text { ) yöntemi kullanılarak } \\
\text { yapılan lenfödem değerlendirnesinde son } \\
\text { altı ay içerisinde seyahat eden hastalarda } \\
\text { uçak yolculuğu ile lenfödem varlığı } \\
\text { arasında önemli bir ilişki } \\
\text { saptanmamıştır. }\end{array}$ \\
\hline $\begin{array}{l}\text { McLaughlin } \\
\text { et al. } \\
(2008)^{27}\end{array}$ & $\begin{array}{l}\text { Prospektif } \\
\text { vaka } \\
\text { çalışması } \\
\text { - } 936 \text { hasta }\end{array}$ & $\begin{array}{l}\text { Araştırmaya sentinel lenf nodu biyopsisi } \\
\text { (SLNB) ya da sentinel lenf nodu } \\
\text { biyopsisi/aksiller lenf nodu diseksiyonu } \\
\text { (ALND) yapılan hastalar dahil } \\
\text { edilmiştir. Tüm hastalar için medyan } \\
\text { takip süresi beş yıldır. Hasta tarafından } \\
\text { algılanan lenfödem ve kaçınma } \\
\text { davranışları görüşme yoluyla tespit } \\
\text { edilirken, kol çevresi ölçümleriyle } \\
\text { karşılaştırılmıştır. }\end{array}$ & $\begin{array}{l}\text { SLNB olan hastaların \%3’ü, SLNB/ALND } \\
\text { geçiren hastaların \%27'si kol şişmesi } \\
\text { bildirirken, ölçümlerde bu oran sırasıyla } \\
\text { \%5 ve \%16 olarak tespit edilmiştir. Kol } \\
\text { şişmesi bildiren hastaların \%41'i, bildirim } \\
\text { yapmayan hastaların \%5’inde lenfödem } \\
\text { tespit edilmiştir. Hastaların lenfödemi } \\
\text { ölçmesi ya da algılaması durumunda } \\
\text { daha fazla önlem aldıkları belirlenmiştir. } \\
\text { 10o hasta seyahat düzenini değiştirmiş, } \\
\text { 36'sı ise uçağa binmekten (<=1 saat) } \\
\text { tamamen kaçınmıştır. }\end{array}$ \\
\hline
\end{tabular}




\begin{tabular}{|c|c|c|c|}
\hline $\begin{array}{l}\text { Mak et al. } \\
(2009)^{28}\end{array}$ & $\begin{array}{l}\text { Eşleştirilmiş } \\
\text { vaka kontrol } \\
\text { çalışması } \\
-101 \\
\text { lenfödem } \\
\text { olgusu } \\
\text {-101 } \\
\text { eşleştirilmiş } \\
\text { kontrol }\end{array}$ & $\begin{array}{l}\text { Olgu olarak atanan katılımcılar beş } \\
\text { yıldan daha uzun süre olmamak üzere } \\
\text { lenfödem tanısı konan kişilerdir. } \\
\text { Kontrollerde lenfödem tespit edilmeyen } \\
\text { hastalar ameliyat tarihi, aksillaya } \\
\text { radyasyon alıp almadığı ve kanser } \\
\text { evrelerine göre vakalarla eşleştirilmiştir. } \\
\text { Risk faktörleri, kol morbiditesi ve yaşam } \\
\text { kalitesi hakkında bilgi edinmek için iki } \\
\text { anket kullanılmış ve kol çevresi } \\
\text { ölçümleri yapılmıştır. }\end{array}$ & $\begin{array}{l}\text { Olguların 74'ünde orta-şiddetli lenfödem } \\
\text { ve 27'sinde hafif lenfödem olan vakalar } \\
\text { (101 lenfödem olgusu) ve } 101 \text { kontrol bir } \\
\text { araya toplanmıştır. } \\
\text { Lenfödem ile hava yolculuğu arasında } \\
\text { anlamlı bir ilişki bulunamamıştır. }\end{array}$ \\
\hline $\begin{array}{l}\text { Swenson et } \\
\text { al. }(2009)^{29}\end{array}$ & $\begin{array}{l}\text { Çok bölgeli } \\
\text { retrospektif } \\
\text { vaka kontrol } \\
\text { çalışması } \\
\text {-94 lenfödem } \\
\text { hastası } \\
\text {-94 kontrol } \\
\text { grubu }\end{array}$ & $\begin{array}{l}94 \text { lenfödem hastası ve lenfödem } \\
\text { olmayan } 94 \text { kontrol grubu hastası } \\
\text { aksiller cerrahi türü ve ameliyat tarihine } \\
\text { göre eşleştirilmiştir. } \\
\text { Lenfödem şiddeti kol çevresinin } \\
\text { ölçümüyle tespit edilirken, hastalık ve } \\
\text { tedavi faktörleri grafik inceleme } \\
\text { yöntemiyle toplanmıştır. }\end{array}$ & $\begin{array}{l}\text { Lenfödem hastalarının kontrol } \\
\text { grubundan daha kilolu (BKİ >=25) } \\
\text { oldukları görülmüştür. } \\
\text { Aksiller radyasyon, mastektomi, } \\
\text { kemoterapi, daha fazla pozitif lenf nodu, } \\
\text { ameliyat sonrası sıvı aspirasyonu ve aktif } \\
\text { kanser durumu olma olasılıklarının daha } \\
\text { yüksek olduğu bulunmuştur. } \\
94 \text { hastanın 47’si uçak yolculuğundan } \\
\text { kaçınmıştır. Yapılan çok değişkenli } \\
\text { analizde uçak yolculuğunun lenfödemle } \\
\text { ilişkili olmadığ belirlenmiştir. Fazla } \\
\text { kilolu olmak lenfödemle ilişkili } \\
\text { değiştirilebilir risk faktörüdür. }\end{array}$ \\
\hline
\end{tabular}

Tablo 1. Lenfödem ve uçak seyahati ilişkisi inceleyen çalışmalar (devam)

\begin{tabular}{|c|c|c|c|}
\hline Yazar/lar & $\begin{array}{l}\text { Çalışmanın } \\
\text { Türü / } \\
\text { Vaka Sayısı }\end{array}$ & $\begin{array}{l}\text { Çalışmanın Metodolojisi } \\
\text { (Kullanılan İçerikler) }\end{array}$ & Elde Edilen Sonuçlar \\
\hline $\begin{array}{l}\text { Showalter et al. } \\
(2013)^{30}\end{array}$ & $\begin{array}{l}\text { Fiziksel } \\
\text { Aktivite ve } \\
\text { Lenfödem } \\
\text { (PAL) } \\
\text { randomize } \\
\text { kontrollü } \\
\text { çalışmasının } \\
\text { prospektif } \\
\text { alt analizi } \\
\text {-295 hasta }\end{array}$ & $\begin{array}{l}\text { Katılımcılardan maruz kaldıkları } \\
\text { 30 farklı potansiyel risk faktörünü } \\
\text { bildirmeleri istenmiştir. Maruziyet } \\
\text { listesi lenfödem uzmanı bir fiziksel } \\
\text { tıp ve rehabilitasyon doktoru } \\
\text { tarafından derlenmiştir. Hastalara } \\
\text { 3,6 ve } 12 \text { aylık sürelerle risk } \\
\text { faktörlerine ilişkin maruziyet } \\
\text { durumları sorgulanmıştır. } \\
\text { Çalışmada hastaların koldaki } \\
\text { şişmeyi değerlendirmek için her } \\
\text { iki kol arasındaki volüm artışı } \\
\text { ölçülmüştür. }\end{array}$ & $\begin{array}{l}\text { Sauna kullanımının etkilenen kolda } \\
\text { şişmeye yol açan faktör olduğu } \\
\text { bulunmuştur. } \\
\text { Uçak yolculuğu ve seyahat irtifasının } \\
\text { lenfödem gelişimi için önemli risk } \\
\text { faktörleri olmadığı belirlenmiştir. }\end{array}$ \\
\hline $\begin{array}{l}\text { Kilbreath et al. } \\
(2016)^{31}\end{array}$ & $\begin{array}{l}\text { Prospektif } \\
\text { kohort } \\
\text { çalışması } \\
-540 \text { hasta } \\
-\end{array}$ & $\begin{array}{l}\text { Çalışmada kadınlar ameliyattan } \\
\text { önce, ameliyattan sonraki } 4 \text { hafta } \\
\text { içinde, } 6,12 \text { ve } 18 \text {. aylarda } \\
\text { değerlendirilmiştir. Hastalar } 18 \\
\text { aylık değerlendirmeye kadar } \\
\text { haftalık günlüklerini } \\
\text { tamamlamaları konusunda } \\
\text { eğitilmişlerdir. Bu günlüklerde } \\
\text { lenfödem gelişimi için risk } \\
\text { faktörlerine maruziyet } \\
\text { durumlarını kaydetmeleri } \\
\text { istenmiştir. }\end{array}$ & $\begin{array}{l}\text { Yurtiçi uçak seyahati sayısı ile lenfödem } \\
\text { gelişimi arasında anlamlı bir ilişki } \\
\text { saptanmamıştır }\end{array}$ \\
\hline $\begin{array}{l}\text { Ferguson et al. } \\
(2016)^{32}\end{array}$ & $\begin{array}{l}\text { Prospektif } \\
\text { kohort } \\
\text { çalışması }\end{array}$ & $\begin{array}{l}\text { İki taraflı kol hacmi ölçümleri } \\
\text { ameliyat öncesi ve sonrası } \\
\text { dönemde perometre kullanılarak }\end{array}$ & $\begin{array}{l}\text { Çalışmada risk altındaki kolda hava } \\
\text { yolculuğu, kan basıncı ölçümleri, kan } \\
\text { alımı, enjeksiyonlar ile kol hacim artışı }\end{array}$ \\
\hline
\end{tabular}




\begin{tabular}{|c|c|c|c|}
\hline & -3041 ölçüm & $\begin{array}{l}\text { yapılmış, her ölçümde hastalar kan } \\
\text { aldırma, enjeksiyon, kan basıncı } \\
\text { ölçümü, etkilenen kola travma ve } \\
\text { uçuş sayısını rapor etmişlerdir. }\end{array}$ & $\begin{array}{l}\text { arasında anlamlı bir ilişki } \\
\text { saptanmamıştır. } \\
\text { Yapılan ölçümlerde nispi hacim } \\
\text { değişikliği veya ağırlığa göre ayarlanmış } \\
\text { değişiklik artışı ile kan alımı, enjeksiyon, } \\
\text { uçuş sayısı (<3) veya uçuş süresi (<12 } \\
\text { saat) arasında anlamlı bir ilişki olmadığı } \\
\text { belirlenmiştir. } \\
\text { Koldaki hacim artışında BKİ>=25 } \\
\text { olması, aksiller lenf nodu diseksiyonu, } \\
\text { rejyonel lenf nodu ışınlaması ve selülitin } \\
\text { önemli risk faktörleri olduğu } \\
\text { belirlenmiştir. Araştırma ipsilateral kan } \\
\text { alımı, enjeksiyonlar, kan basıncı } \\
\text { ölçümleri ve hava yolculuğunun kol } \\
\text { hacmindeki artışlarla ilişkili } \\
\text { olmayabileceğini düşündürmüştür }\end{array}$ \\
\hline Co et al. (2018) 33 & $\begin{array}{l}\text { Sistematik } \\
\text { derleme } \\
-23 \text { çalışma }\end{array}$ & $\begin{array}{l}\text { Medline, Embase, CINAHL ve } \\
\text { Cochrane veritabanları } \\
\text { taranmıştır. Dört alt kategoride } \\
\text { ayrı ayrı literatür taraması ve } \\
\text { inceleme yapılmıştır: yara ve } \\
\text { drenler, derin ven trombozu } \\
\text { (DVT), meme implantları ve } \\
\text { lenfödem. }\end{array}$ & $\begin{array}{l}\text { Postoperatif mastektomi yaraları ve } \\
\text { drenleri üzerine uçak seyahatinin } \\
\text { olumsuz etkilerini tespit etmek için } \\
\text { mevcut literatürdeki kanıtlar sınırlıdır. } \\
\text { Benzer şekilde, meme implantları } \\
\text { üzerindeki olumsuz etkilerinin } \\
\text { belirlenmesine ilişkin çalışmalar vaka } \\
\text { raporları ve ex vivo deneylerle sınırlıdır. } \\
\text { 12 çalışmanın sistematik bir derlemesi, } \\
\text { uçak seyahatinin meme kanseri cerrahisi } \\
\text { sonrası üst ekstremite lenfödemiyle } \\
\text { ilişkili olmadığına ulaşmıştır. } \\
\text { Derin ven trombozu hava yolculuğundan } \\
\text { sonra bilinen bir komplikasyondur ve } \\
\text { malignite derin ven trombozu için } \\
\text { bilinen bir risk faktörüdür. } \\
\text { Uçak seyahati yaparken tamoksifenin } \\
\text { devam etmesinin güvenliğine dair yeterli } \\
\text { kanıt yoktur. } \\
\text { Postoperatif meme kanseri hastalarında } \\
\text { sistemik DVT profilaksisinin kullanımını } \\
\text { destekleyen kanıtlar sınırlıdır. } \\
\text { Retrospektif çalışmadan elde edilen } \\
\text { kanıtlar, mekanik antiembolizm } \\
\text { cihazlarının ve erken mobilizasyonun } \\
\text { gerekli olan tek önlem olduğunu } \\
\text { göstermiştir. } \\
\text { Meme kanseri cerrahisi sonrası } \\
\text { hastalarda uçak seyahati genellikle } \\
\text { güvenlidir. }\end{array}$ \\
\hline
\end{tabular}

\section{Gelişme}

\section{Meme Cerrahisi Sonrası Lenfödem}

Cerrahi, radyoterapi, kemoterapi, hormonal terapi gibi birçok tedavinin meme kanserinde etkili olduğu bilinmektedir. Ancak uygulanan tedavilere bağlı olarak gelişebilen önemli komplikasyonlardan biri olan lenfödem, hem hastalar hem de sağlık profesyonelleri açısından zorlu klinik bir tablodur. Bireylerde fiziksel, sosyal ve psikolojik birtakım sorunlara yol açan lenfödem, \%6-\%54 arasında değişen oranlarda görülmektedir34. Bu bağlamda yapılmış uzun dönem araştırmaları önemli sonuçlar sağlamaktadır. Bevilacqua ve ark. (2012) yaptıkları 
çalışmada beş yıllık kümülatif lenfödem insidansı \%30.3 olarak tespit edilirken35, bir diğer kohort araştırmasında ise insidans \%67 olarak bulunmuştur ${ }^{6}$. Meme kanseri cerrahisi sonrası 10 ylllık takipte lenfödem sıklığı ve risk faktörlerinin değerlendirildiği çalışmada ise, bu oran iki yıllık takipte \%13.5, beş yılda \%30.2 ve 10 yılda \%41.1 olarak belirlenmiştir37.

Lenfödem, belirli kanser tiplerinin yanı sıra lenf damarlarının çıkarıldığı ya da tıkandığı bazı cerrahi işlemler sonrasında da görülebilmektedir. Özellikle radikal mastektomi ameliyatında çok sayıda lenf damarı çıkarıldığından meme ve kol bölgelerinden sıvının uzaklaştırılması bozulmakta, ödem ve doku aralıklarının şişmesine yol açmaktadır38. Az sayıda lenf nodu diseksiyonu yapılan bu tip cerrahi operasyonlardan sonra, lenf damarlarının bir kısmı zamanla yeniden gelişeceği (lenfanjiyogenez) için meydana gelen hücreler arası ödem genellikle geçici olmaktadır 38,39 .

Postnatal, enfeksiyöz, iyatrojenik ya da lenfatik sisteme ilişkin travmatizan faktörlere bağlı sekonder lenfödem ortaya çıkmaktadır. Meme kanseri tedavisinin en yaygın görülen komplikasyonudur. Meme kanserinin tedavisinde aksiller lenf diseksiyonu uygulanan her beş hastadan birinde lenfödem geliştiği belirtilmektedir ${ }^{40}$.

Meme kanseri kaynaklı lenfödemin önlenebilmesi için semptomların erken dönemde değerlendirilmesi oldukça önemlidir. Çünkü bu kronik görüntünün gelişiminin başlangıcında, ekstremitede gözle görülür bir hacim artışı söz konusu değildir. Hacim artışına bağlı olarak; etkilenen ekstremitede şişlik, gerginlik, ağrı, ağırlık, sertlik, uyuşma, karıncalanma, uzuvda yorgunluk, zayıflı ile hareketlerde bozulma gibi birçok semptomla karşı karşıya kalınmaktadır ${ }^{41,42}$. Meme kanseri sonrası lenfödem gelişimine yol açan birçok faktör bulunmaktadır. Hastanın yaşı, kanserin evresi (erken evrede daha az görülmekte), cilt enfeksiyonu, etkilenen ekstremitenin uzun süreli kullanımı, yüksek beden kitle indeksi, majör operasyonlar, postoperatif komplikasyonların varlığı, mastektomi cerrahisinin başarısı ve aksiller lenf nodu diseksiyonu, radyasyon tedavisi ile omuz hareketlerinin azalması gibi birtakım nedenlerin lenfödem gelişme olasılığını arttırdığı bilinmektedir43-46.

Dünya çapında uçak seyahati hızla artmakta ve popüler hale gelmektedir. Uluslararası Hava Taşımacılığı Birliği, 2016 yılında 3.8 milyar olan yolcu sayısının 2035 yılına gelindiğinde 7.2 milyara ulaşacağını öngörmektedir. Bu veriler her yıl yaklaşık \%3.7 oranında yolcu sayısında bir artışa karşllık gelmektedir47. Havayolu seyahati, insanlara sunduğu birçok avantaja rağmen meme kanseri cerrahisi geçiren bireyler için önemli bir engel halini almaktadır ${ }^{28,33,47,48}$. Özellikle meme kanseri cerrahisi sonrası yapılan uçak seyahatinin, lenfödemi şiddetlendirdiği görüşü yaygındır. Bireylerin sosyal ve çalışma yaşamlarını önemli ölçüde etkileyen lenfödemin gelişiminde, irtifadaki düşük kabin basıncı ile uçağın yükseliş ve inişi sırasında meydana gelen kabin basıncındaki belirgin değişikliklerin etkili olduğu düşünülmektedir46.

\section{Uçak Seyahatinin Lenfödem Gelişimi Üzerine Etkileri}

Günümüzün modern uçakları, insan fizyolojisine uygun olmayan yüksek irtifalarda ulaşım imkânı sağlamasına karşın, basınçlandırma sistemleri sayesinde yolcular ve mürettebat için genellikle herhangi bir sağlık sorunu teşkil etmez. Yükseklik arttıkça hava basıncı düşmekle birlikte, aşırı irtifadaki seyahatlerde uçak kabinleri belirli bir basınç altında kalmaktadır28,33,46-48. Uçak türbin motorundan çıkan basınçlı havanın pompalanmasıyla sağlanan bu ortam, uçak yolculuğu sırasında da korunmaktadır ${ }^{46}$. Bu sayede yolculuk esnasında uçak içerisindeki kabin basıncı, deniz seviyesindeki atmosfer basıncından daha düşük hale getirilmektedir. Basınç farklılıkları her ne kadar ciddi sağlık sorunlarına yol açmasa da lenfatik yapılara müdahaleyi gerektiren meme cerrahisi/leri sonrasında bireylerde lenfödem tablosu ile sonuçlanabilmektedir ${ }^{28,33,46-48}$. Özellikle 
yolculuk esnasında düşük kabin basıncı ile birlikte dehidratasyon, hareket sınırlılığı ve uçak içerisindeki hipobarik ortam gibi faktörlerin lenfödem gelişim sürecini hızlandırdığı belirtilmektedir 49 .

\section{Uçak Seyahatinin Lenfödem Gelişimi Üzerindeki Etkisini Azaltmada Yapılabilecek Girişimler}

Geçmişten günümüze lenfödem için risk azaltma stratejileri, etkilenen ekstremitenin lenfatik sistem üzerindeki stresini azaltmak olmuştur49. Bu bağlamda tartışllan konulardan birisi de meme kanseri ve cerrahisi sonrası uçak seyahati ve olası lenfödem gelişme durumudur. Ancak lenfödem patofizyolojisine ilişkin bilgilerin sınırlı olması, önlenmesine ve iyileştirilmesine yönelik müdahalelerin yetersiz kalmasına yol açmıştır. Lenfödemin önlenmesine yönelik manuel (elle) lenf drenajı, egzersiz, cilt bakımı, hasta eğitimi, izlem ve erken müdahale gibi birtakım standart uygulamalar söz konusudur5o. Lenfödemin iyileştirilmesinden ziyade önlenmesine yönelik tedbirler daha önemli ve tercih edilebilirdir. Bu bağlamda Ulusal Lenfödem Ağı, risk altındaki kolda enjeksiyon ve kan aldırma vb. işlemler ile kan basıncı ölçümü, turnike gibi uygulamalardan kaçınılması, uçak seyahati sırasında kompresyon giysilerinin kullanılması, cilt enfeksiyonunun önlenmesi gibi birtakım önerilere yer vermişlerdir ${ }^{1}$. Bazı çalışmalar, uçak seyahatinin meme kanseri sonrasında lenfödem gelişimi için bir risk teşkil etmediği, dolayısıyla rutin olarak kompresyon giysilerinin kullanılmasının gerekli olmadığını öne sürmektedir30-52. Yakın zamanda Ferguson ve ark. (2016) yaptıkları prospektif çalışmada riskli olaylar ile kol hacmindeki değişiklikler arasındaki ilişki incelenmiş, risk altındaki kolda uçak seyahati ile kol hacmi artışı arasında anlamlı bir ilişki olmadığı tespit edilmiştir32. Ancak bu konuya ilişkin yapılan çalışmaların sınırlı örneklem ve sayıda olması, genel geçer kabul edilebilir verilerin ortaya konmasını güçleştirmektedir.

\section{Uçak Seyahati ve Kompresyon Giysileri}

Meme kanseri ve tedavisi sonrası lenfödem patofizyolojisine ilişkin görüşler, kompresyon giysilerinin önleyici tedbirler arasında yer alması gerektiği düşüncesinde birleşmektedir53,54. Hatta lenf nodu diseksiyonu olan hastaların uçak seyahatinden kaçınmaları ya da yolculuk esnasında lenfödem olmasa bile kompresyon giysileri giymeleri önerilir 55,56 . Ancak bu önerileri destekleyen kanıt değeri yüksek kılavuzların eksikliği bilim dünyasındaki bir açığı gözler önüne sermektedir57. Konuya ilişkin Casley-Smith (1996) tarafından yapılan retrospektif anket çalışmasında (Kanıt düzeyi IV) uçakta oluşan düşük kabin basıncı, damarların ve lenfatiklerin tıkanması, kas pompalanmasının azalmasının lenfödem gelişimini tetikleyebileceği, kompresyon giysilerinin kullanılmasının önleyici olabileceği belirtilmiştir ${ }^{24}$.

Uçak seyahati ile meme kanseri ve tedavisi nedenli lenfödem arasında anlamlı bir ilişkiyi ortaya koyan çalışmalar olduğu gibi aksini iddia eden araştırmalar da söz konusudur. Hayes ve arkadaşlarının meme kanseri tedavisinden altı ay sonra lenfödem prevalansını belirlemek ve risk faktörlerini ortaya koymak amacıyla yaptıkları çalışmada (2005), bu süre içerisinde gerçekleştirilen uçak seyahatleri ile lenfödem arasında anlamlı bir ilişki görülmemiştir ${ }^{26}$. Meme kanseri cerrahisi sonrası lenfödem göstergelerini değerlendirmek amacıyla yapılan vaka kontrol çalışmasında yapılan çok değişkenli analizde lenfödem ile hava yolculuğu arasında anlamlı bir ilişki görülmezken, 47 hastanın cerrahi sonrası uçakla seyahat etmekten kaçındığı tespit edilmiştir ${ }^{29}$. Kilbreath ve arkadaşlarının aksiller cerrahiye bağlı lenfödem riski yüksek hastaları belirlemek amacıyla yaptıkları prospektif çalışmada (2016), yurtiçi uçak seyahati sayısı ile lenfödem gelişimi arasında anlamlı bir ilişki saptanmamıştır ${ }^{3}{ }^{1}$. Meme kanseriyle ilişkili risk faktörleri, önlem kılavuzları, prospektif tarama, erken müdahale, cerrahi ve cerrahi olmayan tekniklerle ilgili kanıtların gözden geçirilmesi amacıyla yapılan bir diğer çalışmada (2018) da uçak 
seyahatinin hastalar için önemli bir risk faktörü olmadığı sonucuna ulaşmıştır58. Benzer şekilde Co ve arkadaşlarının 2018 yılında yaptıkları her iki çalışmada da havayolu seyahatinin hastalar için genellikle güvenliği olduğu ve lenfödem gelişimini olumsuz yönde etkilemediği bulgusuna varmıştır33,46. Meme kanseri/cerrahisi geçiren hastalarda lenfödem gelişimi ile hava yolu seyahati arasındaki sınırlı sayıdaki çalışma bireyler üzerinde önemli fiziksel, psikososyal ve duygusal etkilere yol açmıştır ${ }^{13}$. Hastaların büyük bir kısmı kısa mesafelerdeki seyahatlerde dahil olmak üzere hava yolu ulaşımını oldukça kısıtlamış, hatta bazıları bu fikirden tamamen uzaklaşmıştır27,29. McLaughlin ve arkadaşlarının yaptıkları çalışmada (2008), 936 hastanın 100'ünün seyahat şeklini değiştirdiği, altısının ise kısa mesafeli uçuşları (<1saat) tercih ettiği belirlenmiştir. Ayrıca hastaların lenfödemi ölçmesi ya da algılaması durumunda, uçak seyahati sırasında profilaktik kompresyon giysilerini daha fazla tercih ettikleri görülmüştür. Hastaların davranış biçimlerinde görülen bu değişimlerde lenfödem gelişimi/lenfödemin kötüleşmesi olasılığına dair yaşanan korku ve endişelerin belirgin olduğu söylenmektedir ${ }^{27}$. Bir başka çalışmada ise hastaların yarısının uçak seyahati yaptığı, bunların sadece \%27'sinin yurtdışına seyahat ettiği belirlenmiştir. Bu hastaların \%24'ünün lenfödem için önlemler aldığı, önlem alanların \%9o’ının kompresyon teknikleri kullandığı belirlenmiştir.

Uçak seyahati yapmayan ve uçmaktan korkan kadın sayısı 22 (\%15) olarak tespit edilmiştir. Buna ek olarak, uçak seyahati yapmasına rağmen korku yaşayan kadın sayısının 24 (\%17) olduğu saptanmıştır. Ancak uçak seyahati yapan ve yapmayan hastalar arasında lenfödem görülme oranları bakımından anlamlı bir farklılık belirlenmemiştir. Uçuş sırasında lenfödem önlemi alan hastalarda lenfödem görülme olasılığının önlem almayanlara göre daha yüksek olduğu anlaşılmıştır. Ancak çalışmada uçuştan önce lenfödem olan hastalarda önlem alma durumlarına göre geçici şişlik bildirimleri arasında farklılık görülmemiştir ${ }^{25}$. Dolayısıyla, hastaların uçak seyahatine bağlı meme cerrahisi sonrası lenfödem gelişimine ilişkin yeterli bilgiye sahip olmadıkları için korku ve endişenin yaşadıkları ve sosyal yaşam aktivitelerini kısıtladığı anlaşılmaktadır. Lenfödem gelişme olasılığı yüksek olan ve bunu deneyimleyen bireylerin uçuş esnasında önlem alan grup olması, hastaların genel iyilik hallerini koruma çabası içerisinde olduklarını ve olası kötü durumlara ilişkin anksiyete ve stres yaşadıkları algısını yaratmaktadır. Hastaların ve klinisyenlerin bu konuda eğitilmeleri, bireye özgü bakım önerileri geliştirilmesi gerekmektedir. İlerleyen teknolojinin uçak endüstrisinde de etkisini göstermesiyle birlikte tüm hastaların güvenle seyahat etmeleri beklenmektedir ve bu en doğal haklarıdır. Hava yolu ulaşımının popüler hale geldiği günümüz dünyasında, meme kanseri ve tedavisi nedenli lenfödemin bireylerin günlük ve sosyal yaşamlarını olumsuz yönde etkilediği açıtır ${ }^{13}$. Yapılan çalışmalarda hastaların, meme kanseri ve tedavisi sonrası lenfödemin önlenmesine yönelik uygulamalara ilişkin yeterli bilgi ve beceriye sahip olmadıkları görülmektedir. Özellikle uçak seyahatinin meme cerrahisi sonrası lenfödem gelişimi üzerindeki etkilerinin hastalardaki belirsizliğini koruması, bireyleri davranışsal birtakım yeni önlemleri almaya itmiştir. $\mathrm{Bu}$ önlemlerin bir kısmı, önerilen kompresyon giysilerinin kullanılması olurken, bir kısmı ise seyahatlerin ertelenmesi, seyahat süre ya da yöntemlerinde birtakım değişikliklere gidilmesi şeklinde olmuştur. Bu nedenle hastaların konuya ilişkin bilgilendirilmesinde hemşirelere önemli görev ve sorumluluklar düşmektedir. Hastalarda lenfödem varlığında, hekim tarafından reçete edilen ve yürütülen dekonjestif tedavi süreçlerinin 55 aksine lenfödem risk azaltma stratejilerine ilişkin tartışmalar sürmektedir56.

\section{Sonuç}

Yapılan incelemeler, konuya ilişkin randomize kontrollü çalışmaların olmadığg ve araştırmaların sınırlı sayıda kaldığını ortaya koymaktadır. Bu sınırlı sayıdaki çalışmalardan bir kısmı uçak seyahatinin lenfödem tablosunu negatif yönde etkilediğini belirtmektedir. Aksine uçuş sayı ve 
süresine bakılmaksızın aralarında herhangi bir ilişki olmadığını ortaya koyan araştırmalar da söz konusudur. Bu bağlamda konuya ilişkin yüksek kanıt düzeylerine ulaşabilecek yargılara varabilmek için, ideal örnekleme sahip, metodolojisi iyi kurgulanmış, prospektif, randomize kontrollü çalışmalara ihtiyaç olduğu düşünülmektedir.

\section{KAYNAKLAR}

1. Thorat MA, Balasubramanian R. Breast cancer prevention in high-risk women. Best Pract Res Clin Obstet Gynaecol. 2020;65:18-31.

2. Joshi D. Breast cancer treatment: survival facts and associated side effects. International Journal of Innovative Science and Technology. 2019;4(1):33-39.

3. World Health Organization. Cancer. WHO. https://www.who.int/news-room/factsheets/detail/cancer. Erişim tarihi 3 Nisan 2020.

4. American Cancer Society. How common is breast cancer. American Cancer Society. https://www.cancer.org/cancer/breast-cancer/about/how-common-is-breastcancer.ht\%20ml. Erişim tarihi 4 Nisan 2020.

5. World Health Organization International Agency for Research on Cancer. Turkey source: globocan 2020. International Agency for Research on Cancer.

https:/gco.iarc.fr/today/data/factsheets/populations/792-turkey-fact-sheets.pdf. Erişim tarihi 4 Nisan 2020.

6. National Cancer Institute. Cancer stat facts: female breast cancer. National Cancer Institute. https://seer.cancer.gov/statfacts/html/breast.html. Erişim tarihi 3 Nisan 2020.

7. Gómez-Raposo C, Zambrana Tévar F, Sereno Moyano M, López Gómez M, Casado E. Male breast cancer. Cancer Treat Rev. 2010;36(6):451-7.

8. Siegel RL, Miller KD, Jemal A. Cancer statistics. CA Cancer J Clin. 2020;70(1):7-30.

9. Kim SY, Han BK, Kim EK, Choi WJ, Choi Y, Kim HH, et al. Breast cancer detected at screening US: Survival rates and clinical-pathologic and imaging factors associated with recurrence. Radiology. 2017;284(2):354-364.

10. Hong JH, Ha KS, Jung JH, et al. Clinical features of male breast cancer: experiences from seven institutions over 20 years. Cancer Res Treat. 2016;48(4):1389-1398.

11. Fontes KP, Veiga DF, Naldoni AC, Sabino-Neto M, Ferreira LM. Physical activity, functional ability, and quality of life after breast cancer surgery. $J$ Plast Reconstr Aesthet Surg. 2019;72(3):394-400.

12. Palesh O, Scheiber C, Kesler S, Mustian K, Koopman C, Schapira L. Management of side effects during and post-treatment in breast cancer survivors. Breast J. 2018;24(2):167-175.

13. Río González Á, Molina-Rueda F, Palacios-Ceña D, Alguacil-Diego IM. Living with lymphoedema-the perspective of cancer patients: A qualitative study. Support Care Cancer. 2018;26(6):2005-2013.

14. İzci F, İlgün AS, Findıklı E, Özmen V. Psychiatric symptoms and psychosocial problems in patients with breast cancer. $J$ Breast Health. 2016;12(3):94-101.

15. Toyserkani NM, Jørgensen MG, Haugaard K, Sørensen JA. Seroma indicates increased risk 
of lymphedema following breast cancer treatment: A retrospective cohort study. Breast. 2017;32:102-104.

16. Lee JS, Jeon HJ, Lee J, Park HY, Yang JD. Treatment of late solidified hematoma in back donor site after breast reconstruction with latissimus dorsi flap: Report of three cases. $B M C$ Surg. 2019;19(1):51.

17. Koehler LA, Haddad TC, Hunter DW, Tuttle TM. Axillary web syndrome following breast cancer surgery: Symptoms, complications, and management strategies. Breast Cancer . 2018;11:13-19.

18. Fakhari S, Atashkhoei S, Pourfathi H, Farzin H, Bilehjani E. Postmastectomy pain syndrome. International Journal of Women's Health and Reproduction Sciences. 2017;5(1):18-23.

19. Fakhari S, Pourfathi H, Farzin H, Bilehjani E. Post-mastectomy phantom breast syndrome. Journal of Obstetrics, Gynecology and Cancer Research. 2017;3(4):137-142.

20. Lovelace DL, McDaniel LR, Golden D. Long-term effects of breast cancer surgery, treatment, and survivor care. J Midwifery Womens Health. 2019;64(6):713-724.

21. Macedo FO, Bergmann A, Koifman RJ, Torres DM, Costa RM, da Silva IF. Axillary surgery in breast cancer: acute postoperative complications in a hospital cohort of women of Rio De Janeiro, Brazil. Mastology. 2018;28(2):80-6.

22. Rząca MS, Łukasiewicz S, Sołowiej K, Stanisławek A, Domżał Drzewicka R. Limitations of functioning in everyday life in women surgically treated for breast cancer. Journal of Education Health and Sport. 2019;9(2):354-361.

23. Schreier AM, Johnson LA, Vohra NA, Muzaffar M, Kyle B. Post-treatment symptoms of pain, anxiety, sleep disturbance, and fatigue in breast cancer survivors. Pain Manag Nurs. 2019;20(2):146-151.

24. Casley Smith JR. Lymphedema initiated by aircraft flights. Aviat Space Environ Med. 1996;67(1):52-6.

25. Graham PH. Compression prophylaxis may increase the potential for flight associated lymphoedema after breast cancer treatment. Breast. 2002;11(1):66-71.

26. Hayes S, Cornish B, Newman B. Comparison of methods to diagnose lymphoedema among breast cancer survivors: 6-month follow-up. Breast Cancer Res Treat. 2005;89(3):221-6.

27. McLaughlin SA, Wright MJ, Morris KT, Giron GL, Sampson MR, Brockway JP, et al. Prevalence of lymphedema in women with breast cancer 5 years after sentinel lymph node biopsy or axillary dissection: Patient perceptions and precautionary behaviors. $J$ Clin Oncol. 2008;26(32):5213-9.

28. Mak SS, Yeo W, Lee YM, et al. Risk factors for the initiation and aggravation of lymphoedema after axillary lymph node dissection for breast cancer. Hong Kong Med J. 2009;15(3 Suppl 4):8-12.

29. Swenson KK, Nissen MJ, Leach JW, Post-White J. Case-control study to evaluate predictors of lymphedema after breast cancer surgery. Oncol Nurs Forum. 2009;36(2):18593.

30. Showalter SL, Brown JC, Cheville AL, Fisher CS, Sataloff D, Schmitz KH. Lifestyle risk 
factors associated with arm swelling among women with breast cancer. Ann Surg Oncol. 2013;20(3):842-849.

31. Kilbreath SL, Refshauge KM, Beith JM, et al. Risk factors for lymphoedema in women with breast cancer: a large prospective cohort. Breast. 2016;28:29-36.

32. Ferguson CM, Swaroop MN, Horick N, et al. Impact of ipsilateral blood draws, injections, blood pressure measurements, and air travel on the risk of lymphedema for patients treated for breast cancer. $J$ Clin Oncol. 2016;34(7):691-8.

33. Co M, Ng J, Kwong A. Air travel safety in postoperative breast cancer patients: A systematic review. Clin Breast Cancer. 2018;18(1):e151-e155.

34. Disipio T, Rye S, Newman B, Hayes S. Incidence of unilateral arm lymphoedema after breast cancer: A systematic review and meta-analysis. Lancet Oncol. 2013;14(6):500-15.

35. Bevilacqua JL, Kattan MW, Changhong Y, et al. Nomograms for predicting the risk of arm lymphedema after axillary dissection in breast cancer. Ann Surg Oncol. 2012;19(8):2580-9.

36. Penn IW, Chang YC, Chuang E, et al. Risk factors and prediction model for persistent breast-cancer-related lymphedema: A 5-year cohort study. Support Care Cancer. 2019;27(3):991-1000.

37. Ribeiro Pereira ACP, Koifman RJ, Bergmann A. Incidence and risk factors of lymphedema after breast cancer treatment: 10 years of follow-up. Breast. 2017;36:67-73.

38. Hall JE. Vücut sıvı bölmeleri: hücre dışı ve hücre içi sıvılar; ödem. In: Çağlayan Yeğen B, ed. Guyton ve Hall Tibbi Fizyoloji. 12. baskı. İstanbul: Nobel Tip Kitabevleri; 2013:285301.

39. Suami H. Anatomical theories of the pathophysiology of cancer-related lymphoedema. Cancers. 2020;12(5):1338.

40. Akezaki Y, Tominaga R, Kikuuchi M, et al. Risk factors for lymphedema in breast cancer survivors following axillary lymph node dissection. Prog Rehabil Med. 2019;4:20190021.

41. Fu MR. Breast cancer-related lymphedema: Symptoms, diagnosis, risk reduction, and management. World J Clin Oncol. 2014;5(3):241-247.

42. Heinze SB, Williams PD. Symptom alleviation and self-care among breast cancer survivors after treatment completion. Clin J Oncol Nurs. 2015;19(3):343-9.

43. Ward LC, Battersby KJ, Kilbreath SL. Airplane travel and lymphedema: A case study. Lymphology. 2009;42(3):139-45.

44. Ochalek K, Gradalski T, Partsch H. Preventing early postoperative arm swelling and lymphedema manifestation by compression sleeves after axillary lymph node interventions in breast cancer patients: A randomized controlled trial. J Pain Symptom Manage. 2017;54(3):346-354.

45. Ugur S, Arıcı C, Yaprak M, et al. Risk factors of breast cancer related lymphedema. Lymphat Res Biol. 2013;11(2):72-5.

46. Co M, Ng J, Kwong A. Air travel and postoperative lymphedema a systematic review. Clin Breast Cancer. 2018;18(1):e151-e155.

47. The International Air Transport Association. Forecasts passenger demand to double over 
20 years. https://www.iata.org/en/pressroom/pr/2016-10-18-02/. Erişim tarihi 7 Nisan 2020.

48. Air Transport Action Grup. The economic \& social benefits of air transport. Air Transport Action Grup.

https://www.icao.int/meetings/wrdss2011/documents/jointworkshop2005/atag socialbe nefitsairtransport.pdf. Erişim tarihi 8 Nisan 2020.

49. Asdourian MS, Skolny MN, Brunelle C, Seward CE, Salama L, Taghian AG. Precautions for breast cancer-related lymphoedema: Risk from air travel, ipsilateral arm blood pressure measurements, skin puncture, extreme temperatures, and cellulitis. Lancet Oncol. 2016;17(9):e392-405.

50. Stuiver MM, ten Tusscher MR, Agasi-Idenburg CS, Lucas C, Aaronson NK, Bossuyt PMM. Conservative interventions for preventing clinically detectable upper-limb lymphoedema in patients who are at risk of developing lymphoedema after breast cancer therapy. Cochrane Database Syst Rev. 2015;(2):CD009765.

51. National Lymphedema Network. Position statement of the national lymphedema network. National Lymphedema Network. https://lymphnet.org/position-papers. Erişim tarihi 9 Nisan 2020.

52. Kilbreath SL, Ward LC, Lane K, et al. Effect of air travel on lymphedema risk in women with history of breast cancer. Breast Cancer Res Treat. 2010;120(3):649-54.

53. Hansdorfer-Korzon R, Teodorczyk J, Gruszecka A, Lass P. Are compression corsets beneficial for the treatment of breast cancer-related lymphedema? New opportunities in physiotherapy treatment a preliminary report. Onco Targets Ther. 2016;9:2089-98.

54. Ochałek K, Partsch H, Szygula Z. Prophylactic compression after breast cancer surgery. Veins and Lymphatics. 2018;7(7993):144.

55. American Cancer Society. What the patient can do. American Cancer Society. https://www.cancer.org/treatment/treatments-and-side-effects/physical-sideeffects/lymphedema/for-people-with-lymphedema.html.Erişim tarihi 7 Nisan 2020.

56. National Lymphedema Network. Topic: Lymphedema risk reduction practices. https://klosetraining.com/wp-content/uploads/2015/05/NLNpractices.pdf. Erişim tarihi 7 Nisan 2020.

57. Cemal Y, Pusic A, Mehrara BJ. Preventative measures for lymphedema: Separating fact from fiction. J Am Coll Surg. 2011;213(4):543-51.

58. Gillespie TC, Sayegh HE, Brunelle CL, Daniell KM, Taghian AG. Breast cancer-related lymphedema: Risk factors, precautionary measures, and treatments. Gland Surg. 2018;7(4):379-403. 